\title{
Feasibility of inguinal hernioplasty under local anaesthesia in elderly patients
}

\author{
Bruno Amato ${ }^{1 *}$, Rita Compagna ${ }^{1}$, Gianni Antonio Della Corte ${ }^{1}$, Giovanni Martino ${ }^{1}$, Tommaso Bianco ${ }^{1}$, \\ Guido Coretti ${ }^{1}$, Roberto Rossi ${ }^{1}$, Francesca Fappiano ${ }^{1}$, Giovanni Aprea ${ }^{1}$, Alessandro Puzziello ${ }^{2}$ \\ From XXV National Congress of the Italian Society of Geriatric Surgery \\ Padova, Italy. 10-11 May 2012
}

\begin{abstract}
Background: The aim of this study is to evaluate the feasibility and the safety of hernioplasty under local anaesthesia in elderly patients with significant comorbidity.

Methods: A total of 218 patients underwent inguinal hernia repair with mesh between June 2009 and July 2012. Presence of comorbid conditions and complications were compared between patients younger and older than 70 years.

Results: Hernia repair in older patients were more likely associated with comorbid conditions than in their younger counterparts ( hypertension: $25 \%$ vs $8.16 \%$; cardiovascular diseases: $50 \%$ vs 22\%; benign prostatic hypertrophy $60 \%$ vs $30 \%$ ). The most common postoperative complications in both groups were recurrence, wound infection, urinary retention. There was a slightly higher rate of complication in elderly group.
\end{abstract}

Conclusions: Inguinal hernia repair with local anaesthesia is quite safe and results in a good success rate in elderly patients despite a higher rate of comorbidity typical of this kind of patient.

\section{Background}

Inguinal hernia is a very common disease and it is more frequent in elderly than in younger patients. The incidence rises from 11 per 10,000 person-years aged 16-24 years to 200 per 10,000 person-years aged 75 years and above [1]. Inguinal hernia repair is one of the most commonly performed operations worldwide [2]. Moreover the demand for surgical services for inguinal hernia is increasing due to an increase of an ageing population [3]. This pathology causes aching discomfort and an unsightly swelling and it is established that hernioplasty gives patients a remarkable improvement of quality of life also in geriatrics [3-5]. In addition, a routine elective operation allow us to avoid acute complications like strangulation, intestinal obstruction, and infarction that

\footnotetext{
* Correspondence: bruno.amato@unina.it

'Department of General, Geriatric, Oncologic Surgery and Advanced Technologies, University of Naples Federico II, Via S. Pansini,5 - 801311 Napoli, Italy

Full list of author information is available at the end of the article
}

are the most important complications of untreated hernia, and are potentially life-threatening [6].

According to the literature the safest approach to geriatric patients is to perform hernioplasty in open surgery [7] using local anaesthesia $[8,9]$ but some authors suggests that it is better to take a watchful waiting approach especially in asymptomatic patients $[10,11]$. In our study we evaluate the impact of hernioplasty in local anesthesia in patients younger and older than 70 years. We compared the frequency of complications and comorbidity in the two groups in order to verify the feasibility and safety of this approach in elderly.

\section{Methods}

In the study we included patients with inguinal hernia that reached our department in the period between June 2009 and July 2012. Patients with recurrence, bilateral hernia, large size hernia and all cases that underwent general anaesthesia were excluded from the study. A total of 218 hernioplasties were performed by resident surgeons in local anaesthesia, 98 of these were patients under 70 years 
and 120 patients were over this age. All procedures were performed as described by Rutkow and Robbins [12] or with Lichtenstein techniques with standard-weight polypropylene mesh [13]. Prophylactic antibiotics were not used [14]. American Society of Anaesthesiologists (ASA) grade 1 and 2 patients underwent deep sedation (midazolam, fentanyl) combined with a field block of local anaesthesia (lidocaine without adrenaline) and were monitored by pulse oximetry. For ASA grade 3 and 4 patients procedures were performed in the presence of the anaesthetist and deep sedation was not used $[9,15,16]$. Comorbidity was registered in the pre-operative time. After surgery patients were examined after 1 week and a second time after 1 month in order to evaluate the presence of postoperative complications.

\section{Results}

None of the 218 procedures were complicated by any sideeffects due to the anesthetic techniques or any other procedure-related complication and there were no deaths. There was a higher rate of comorbidity in the group of over 70 years of age. The main associated illnesses that were observed are: benign prostatic hypertrophy (BPH $60 \%$ in over 70 and $30 \%$ in under 70 ), cardiovascular diseases ( CD $50 \%$ in over 70 and $22 \%$ in under 70 ), hypertension ( $25 \%$ in over 70 and $8.16 \%$ in under 70 ), chronic obstructive pulmonary disease (COPD; $12.5 \%$ in over 70 and $6.12 \%$ in under 70). Other comorbidities that we found were obesity, diabetes, hepatic cirrhosis and renal failure [Table 1]. Intraoperative complications that occurred were severe bleeding (5 cases) and arrhythmia (3 cases). Post-operative complications that occurred were: recurrence (12 cases), wound infection (11 cases),nerve entrapment (10 cases), mesh infection (6 cases), urinary retention (5 cases), and wound hematoma (4 cases). There was a slightly higher rate of complications in the elderly group, in fact recurrence occurred in $7.5 \%$ of older versus $3.6 \%$, wound infections $6.6 \%$ versus $3.6 \%$, mesh infection

Table 1 Patients characteristics

\begin{tabular}{lll}
\hline$N=218$ & & \\
\hline AGE & $\begin{array}{l}\text { Under } 70 \\
98(45 \%)\end{array}$ & $\begin{array}{l}\text { Over 70 } \\
120(55 \%)\end{array}$ \\
\hline ASA 1 -2 & $124(76 \%)$ & $39(23 \%)$ \\
ASA 3-4 & $8(14.5 \%)$ & $47(85.4 \%)$ \\
OBESITY & $15(15.3 \%)$ & $8(7 \%)$ \\
HYPERTENSION & $8(8.16 \%)$ & $30(25 \%)$ \\
CD & $22(22 \%)$ & $60(50 \%)$ \\
DIABETES & $5(5.1 \%)$ & $12(10 \%)$ \\
BPH & $30(30 \%)$ & $72(60 \%)$ \\
CIRRHOSIS / HEPATITIS & $2(2.04 \%)$ & $11(9 \%)$ \\
RENAL FAILURE & $1(1.04 \%)$ & $4(3.3 \%)$ \\
COPD & $6(15 \%)$ & $15(12.5 \%)$ \\
\hline
\end{tabular}

Table 2 Complications

\begin{tabular}{lll}
\hline$N=218$ & & \\
\hline AGE & $\begin{array}{l}\text { Under } 70 \\
98(45 \%)\end{array}$ & $\begin{array}{l}\text { Over 70 } \\
120(55 \%)\end{array}$ \\
\hline SEVERE BLEEDING & $1(1.02 \%)$ & $4(3.3 \%)$ \\
ARRHYTHMIA & 0 & $3(2.5 \%)$ \\
RECURRENCE & $3(3.6 \%)$ & $9(7.5 \%)$ \\
WOUND HEMATOMA & $1(1.02 \%)$ & $3(2.5 \%)$ \\
WOUND INFECTION & $3(3.6 \%)$ & $8(6.6 \%)$ \\
URINARY RETENTION & $1(1.02 \%)$ & $4(3.3 \%)$ \\
MESH INFECTION & $2(2.04 \%)$ & $4(3.3 \%)$ \\
NERVE ENTRAPMENT & $2(2.04 \%)$ & $8(6.6 \%)$ \\
\hline
\end{tabular}

in $3.3 \%$ versus $2.04 \%$, urinary retention in $3.3 \%$ versus $1.02 \%$ [Table 2]. Overall the complication rate is not particularly high even in patients who have a higher percentage of comorbidity.

\section{Conclusions}

Elective inguinal hernia repair under local anesthetic has a good outcome also in the elderly even if there are significant comorbidities. The slightly higher rate of complications that occurred in older patients is not significant and does not support advising against the use of this surgical approach in elderly. So in our opinion hernioplasty under local anesthesia is quite safe and feasible also in patients over 70 years.

\section{List of abbreviations}

ASA: American Society of Anaesthesiologists; $\mathrm{BPH}$ : benign prostatic hypertrophy; CD: cardiovascular disease; COPD: chronic obstructive pulmonary disease.

\section{Acknowledgements}

This article has been published as part of BMC Surgery Volume 12 Supplement 1, 2012: Selected articles from the XXV National Congress of the Italian Society of Geriatric Surgery. The full contents of the supplement are available online at http://www.biomedcentral.com/bmcsurg/supplements/12/ S1.

\section{Author details}

'Department of General, Geriatric, Oncologic Surgery and Advanced Technologies, University of Naples Federico II, Via S. Pansini,5 - 801311 Napoli, Italy. ${ }^{2}$ Departmet of Medical and Surgical Sciences, University Magna Graecia, Catanzaro, Italy.

\section{Authors' contributions}

BA: conception and design, interpretation of data, given final approval of the version to be published; RC: acquisition of data, drafting the manuscript, given final approval of the version to be published; ADC: acquisition of data, drafting the manuscript, given final approval of the version to be published; GM: acquisition of data, drafting the manuscript, given final approval of the version to be published; TB: acquisition of data, drafting the manuscript, given final approval of the version to be published; GC: acquisition of data, drafting the manuscript, given final approval of the version to be published; RR: acquisition of data, drafting the manuscript, given final approval of the version to be published; FF: acquisition of data, drafting the manuscript, given final approval of the version to be published; GA, AP: conception and design, given final approval of the version to be published. 


\section{Competing interests}

The authors declare that they have no competing interests.

Published: 15 November 2012

\section{References}

1. Chow A, Purkatyastha S, Athanasiou T, Tekkis P, Darzi A: Inguinal hernia. BMJ Clin Evid 2007, 4:1-20.

2. Baskerville PA, Jarret PEM: Day case inguinal hernia. Ann R Coll Surg Engl 1983, 65:224-225.

3. Turrentine FE, Wang H, Simpson VB, et al: Surgical risk factors, morbidity, and mortality in elderly patients. J Am Coll Surg 2006, 203:865-877.

4. Patti R, Aiello P, Di Vita G: Improvement of quality of life in elderly after inguinal hernioplasty. In Part of the Supplement: XXIII Annual Meeting of the Italian Society of Geriatric Surgery; 24 August 2011 BMC Geriatrics 2011, 11(Suppl 1):A44.

5. Zieren J, Zieren HU, Wenger F, Muller JM: Repair of inguinal hernia in elderly. Results of the plug-and-patch repair with special reference to quality of life. Chirurg 2000, 71(5):564-567.

6. Nehme AE: Groin hernias in elderly patients. Management and prognosis. Am J Surg 1983, 146:257-260.

7. Pokorny H, Klinger A, Schmid T, Fortelny R, Scheyer M, et al: Recurrence and complications after laparoscopic versus open inguinal hernia repair: results of a prospective randomized multicenter trial. Hernia 2008, 12:385-389.

8. Sanjay P, Leaver H, Shaikh I, Woodward A: Lichtenstein hernia repair under different anaesthetic techniques with special emphasis on outcomes in older people. Austral. J. on Ageing 2011, 30(2):93-97.

9. Nienhuijs SW, Remijn EEG, Rosman C: Hernia repair in elderly patients under unmonitored local anaesthesia is feasible. Hernia 2005, 9:218-222.

10. Fitzgibbons RJ Jr, Giobbie-Hurder A, Gibbs JO, et al: Watchful waiting vs. repair of inguinal hernia in minimally symptomatic men: a randomized clinical trial. JAMA 2006, 295:285-292.

11. O' Dwyer PJ, Norrie J, Alani A, et al: Observation or operation for patients with an asymptomatic inguinal hernia: a randomized clinical trial. Ann Surg 2006, 244:167-173.

12. Robbins AW, Rutkow IM: Mesh plug repair and groin hernia surgery. Surg Clin North AM 1998, 78:1007-1023.

13. Kurzer M, Belsham PA, Kark AE: The Lichtenstein repair for groin hernias. Surg Clin North Am 2003, 83:1099-1117.

14. Simons MP, Aufenacker T, Bouillot JL, Campanelli G, et al: European Hernia Society guidelines on the treatment of inguinal hernia in adult patient. Hernia 2009, 13:343-403.

15. Rispoli C, Rocco N, lannone L, Compagna R, De Magistris L, Braun A, Amato $B$ : Developing guidelines in geriatric surgery: role of the grade system. BMC Geriatrics 2009, 9(SUPPL. 1), Article n.A99.

16. Amato B, Moja L, Panico S, Persico G, Rispoli C, Rocco N, Moschetti I: Shouldice technique versus other open techniques for inguinal hernia repair. ( Review ). Cochrane database of systematic reviews (Online) 2012, 4: CD001543.

doi:10.1186/1471-2482-12-S1-S2

Cite this article as: Amato et al:. Feasibility of inguinal hernioplasty under local anaesthesia in elderly patients. BMC Surgery 2012

12(Suppl 1):S2.

\section{Submit your next manuscript to BioMed Central and take full advantage of:}

- Convenient online submission

- Thorough peer review

- No space constraints or color figure charges

- Immediate publication on acceptance

- Inclusion in PubMed, CAS, Scopus and Google Scholar

- Research which is freely available for redistribution

Submit your manuscript at www.biomedcentral.com/submit
Biomed Central 